\title{
Total zinc absorption in young women, but not fractional zinc absorption, differs between vegetarian and meat-based diets with equal phytic acid content $\uparrow$
}

\author{
Mette Bach Kristensen ${ }^{1}$, Ole Hels ${ }^{1}$, Catrine M. Morberg ${ }^{1}$, Jens Marving ${ }^{2}$, Susanne Bügel ${ }^{1}$ and Inge Tetens ${ }^{1} *$ \\ ${ }^{1}$ Department of Human Nutrition, Center for Advanced Food Studies (LMC), The Royal Veterinary and Agricultural University, \\ Rolighedsvej 30, DK-1958 Frederiksberg C, Denmark \\ ${ }^{2}$ Department of Clinical Physiology and Nuclear Medicine, Rigshospitalet, University of Copenhagen, Denmark
}

(Received 11 January 2005 - Revised 11 March 2005 - Accepted 16 March 2005)

\begin{abstract}
$\mathrm{Zn}$ bioavailability is often lower in vegetarian diets mainly due to low $\mathrm{Zn}$ and high phytic acid contents. The objective of the present study was to determine the fractional and total absorption of $\mathrm{Zn}$ from a vegetarian diet in comparison with meat diets with equal concentrations of phytic acid. A randomized crossover design, comprising three whole-day diet periods of $5 \mathrm{~d}$ each, with a vegetarian diet or diets containing Polish-produced meat or Danish-produced meat, was conducted. Twelve healthy female subjects completed the study. All diets had a high content of phytic acid (1250 $\mu$ mol/d) and in the meat diets the main meals contained $60 \mathrm{~g}$ pork meat. All main meals were extrinsically labelled with the radioactive isotope ${ }^{65} \mathrm{Zn}$ and absorption of $\mathrm{Zn}$ was measured in a whole-body counter. The mean Zn content of the whole-day diet was: Polish meat diet 9.9 (SE 0.14) mg, Danish meat diet 9.4 (SE 0.19) mg and vegetarian diet 7.5 (sE 0.18) mg. No difference was observed in the fractional absorption of Zn (Polish meat diet: 27 (SE 1.2) \%, Danish meat diet: 27 (SE 1.9) \% and vegetarian diet: 23 (SE 2.6) \%). A significantly lower amount of total $\mathrm{Zn}$ was absorbed from the vegetarian diet (mean $\mathrm{Zn}$ absorption of Polish meat diet: 2.7 (SE 0.12) $\mathrm{mg} / \mathrm{d}(P<0.001)$, Danish meat diet: $2.6(\mathrm{SE} 0.17) \mathrm{mg} / \mathrm{d}(P=0.006)$ and vegetarian diet: $1.8(\mathrm{SE} 0.20) \mathrm{mg} / \mathrm{d})$. In conclusion, the vegetarian diet compared with the meat-based diets resulted in lower amounts of absorbed $\mathrm{Zn}$ due to a higher content of $\mathrm{Zn}$ in the meat diets, but no difference was observed in the fractional absorption of $\mathrm{Zn}$.
\end{abstract}

Radioisotope: ${ }^{65} \mathrm{Zn}$ : Bioavailability: Micronutrients: Minerals

$\mathrm{Zn}$ is an essential mineral, incorporated in a substantial number of enzymes with important biological functions. A sub-optimal $\mathrm{Zn}$ status is not easily determined because there is no reliable biochemical indicator for $\mathrm{Zn}$ status and clinical symptoms of deficiency are subtle. The global prevalence of $\mathrm{Zn}$ deficiency is therefore difficult to estimate. Estimates have been made using indirect measures of $\mathrm{Zn}$ consumption patterns and the $\mathrm{Zn}$ content of the global food supply, indicating that approximately $50 \%$ of the world's population is at risk of inadequate $\mathrm{Zn}$ intake (Brown \& Wuehler, 2000). Individuals at risk for low Zn status include people with low absorption, increased losses or increased needs due to growth or pregnancy, enforced by a low intake of $\mathrm{Zn}$ or diets with low bioavailability.

The bioavailability of $\mathrm{Zn}$ is greatly influenced by the composition of the diet, regarding both the concentration of $\mathrm{Zn}$ and the presence of enhancers and inhibitors of $\mathrm{Zn}$ absorption. Animal protein is a rich source of $\mathrm{Zn}$ and in addition has a possible enhancing effect on the overall absorption of $\mathrm{Zn}$ from the diet (Sandström \& Cederblad, 1980; Sandström et al. 1989; Hunt et al. 1991, 1995). It is well known that phytic acid is a strong inhibitor of Zn absorption (Nävert et al. 1985; Sandström et al. 1987a) and a concomitant intake of protein seems to counteract the negative effects on absorption induced by high intakes of phytic acid (Sandström et al. 1980, 1987a,c, 1990).

It is generally accepted that appropriately planned vegetarian diets can be healthy and nutritionally adequate, and that vegetarians have a lower prevalence of certain life-style diseases (Jenkins et al. 2003; Position of the American Dietetic Association and Dietitians of Canada, 2003). However, there are some concerns as to whether vegetarian diets adequately cover the requirements for selected minerals, especially $\mathrm{Fe}$ and $\mathrm{Zn}$. The dietary intake of $\mathrm{Zn}$ in vegetarian diets is lower than or equivalent to the dietary intake of $\mathrm{Zn}$ of omnivores, but the bioavailability in vegetarian diets is generally lower, mainly due to a higher intake of phytic acid (Gibson, 1994; Hunt et al. 1998; Hunt, 2002, 2003; Murphy \& Allen, 2003; Waldmann et al. 2003).

Previous studies identifying an enhanced absorption of $\mathrm{Zn}$ with an additional intake of protein were all meals with varying contents of phytic acid, which is known to be an important determinant for Zn absorption (Sandström \& Cederblad 1980; Sandström et al. 1987c, 1989; Hunt et al. 1991; Johnson \& Walker, 1992; Zheng et al. 1993; Hunt et al. 1995). With a few exceptions (Hunt et al. 1995, 1998) all previous studies have been based on a single meal. In relation to $\mathrm{Fe}$ absorption, which in some 
regards can be compared with $\mathrm{Zn}$ absorption, a potential discrepancy has been identified between single meal studies and whole meal studies, expressed as a higher absorption of $\mathrm{Fe}$ from single meal studies than from whole diet studies (Cook et al. 1991). To our knowledge, no whole-day absorption studies have investigated the bioavailability of $\mathrm{Zn}$ in vegetarian diets compared with meat diets with similar phytic acid contents over five consecutive days.

The aim of the present study was to determine the absorption of $\mathrm{Zn}$ from a vegetarian diet in comparison with a meat diet, with equal concentrations of phytic acid in all diets. The pork meat was produced by a conventional production system in Denmark and Poland.

\section{Subjects and methods}

\section{Subjects}

Sixteen healthy women, mean age 24.2 (SD 3.6) years, with a mean BMI of 21.6 (SD 1.8$) \mathrm{kg} / \mathrm{m}^{2}$, were included in the study. All subjects were omnivores, non-smoking, not pregnant or lactating nor exercising heavily. The subjects did not take any medication or vitamin, mineral or other supplements, and did not donate blood, during and for at least 2 months prior to the study. Eleven subjects took oral contraceptives. Four subjects dropped out of the study; one moved out of the area and the remaining three due to personal reasons.

All subjects were informed, orally and in writing, about the study. Written consent of participation, stating that the subject participated voluntarily and was free to withdraw from the study at any time, was obtained before enrolment. The study protocol was approved by the Ethics Committee of Copenhagen and Frederiksberg (authorization number (KF) 01-197/02) and the National Institute of Radiation Hygiene, Denmark.

\section{Study design}

The absorption of $\mathrm{Zn}$ was measured in a cross-over design with three types of full-day diets, two meat diets and a vegetarian diet, during three periods of $5 \mathrm{~d}$ each (Monday-Friday). The study is a parallel design to the Fe absorption study from vegetable- and meat-based diets by Bach Kristensen et al. (2005). The study design, composition of the test meals and serving procedures are thoroughly described in the mentioned article (Bach Kristensen et al. 2005). All diets consisted of a basic diet, containing relatively high amounts of phytic acid. The two meat diets contained either of two meat sources (longissimus dorsi from pigs produced in Poland or Denmark) and breakfast, lunch and dinner each contained $60 \mathrm{~g}$ meat.

All breakfast, lunch and dinner meals were extrinsically labelled with ${ }^{65} \mathrm{Zn}$ and served at the Department of Human Nutrition. A $2 \mathrm{~d}$ menu cycle was served throughout the week (Table 1) and did not differ between study periods. The study design is illustrated in Fig. 1. The subject's individual weight was recorded at baseline and prior to the final whole-body counting, using the same digital scale.

Meat was obtained from The Danish Institute of Agricultural Sciences, Foulum and The Kielanowski Institute of Animal Physiology and Nutrition as part of the 5th Framework Project SUSPORKQUAL, where it was previously shown that the pork meat from Poland had a higher $\mathrm{Zn}$ content than the Danish
Table 1. Composition of the whole-day diet of $10 \mathrm{MJ}^{*}$

\begin{tabular}{|c|c|c|}
\hline & Meat diet (g) & Vegetarian diet $(\mathrm{g})$ \\
\hline \multicolumn{3}{|l|}{ Breakfast } \\
\hline Whole-grain wheat bread & 100 & 100 \\
\hline Pâté† & 106 & 54 \\
\hline Butter & 15 & 15 \\
\hline Marmalade (raspberry/apricot) $\ddagger$ & 20 & 20 \\
\hline Raisins & 25 & 25 \\
\hline Carbonated drinks & - & 195 \\
\hline \multicolumn{3}{|l|}{ Lunch } \\
\hline Whole-grain wheat bread & 100 & 100 \\
\hline Pâté & 106 & 54 \\
\hline Butter & 15 & 15 \\
\hline Beetroot (pickled)/carrots $\ddagger$ & $30 / 40$ & $30 / 40$ \\
\hline Carbonated drinks & - & 195 \\
\hline \multicolumn{3}{|l|}{ Dinner } \\
\hline Whole-grain pasta /brown rice $£ \S$ & 80 & 80 \\
\hline Casserole\|l & 250 & 205 \\
\hline Whole-grain wheat bread & 40 & 40 \\
\hline Carbonated drinks & - & 195 \\
\hline \multicolumn{3}{|l|}{ Snack } \\
\hline Chocolate & 49 & 49 \\
\hline Dried apricots & 75 & 75 \\
\hline Apple/pearł & 160 & 160 \\
\hline
\end{tabular}

*Breakfast, lunch and dinner each contained $60 \mathrm{~g}$ pork meat in the meat diets (raw weight).

†Pork (only in meat diets), rapeseed oil, eggs, spinach, mushroom, almond, onion, coriander, gelatine, salt.

$\ddagger$ The variation of the $2 \mathrm{~d}$ menu cycle.

$\S$ Raw weight.

|| Pork (only in meat diets), rapeseed oil, mushroom, carrot, canned tomato, tomato purée, onion, garlic, beer, salt.

meat. Breakfast, lunch and dinner meals were extrinsically labelled by adding $1 \mathrm{ml}$ radioisotope solution (Ris $\varnothing$ National Laboratory, Roskilde, Denmark) to the main meal $>16 \mathrm{~h}$ prior to consumption. Each subject received a total dose of $120 \mathrm{kBq}{ }^{65} \mathrm{Zn}$ from the forty-five meals.

Content of protein, fat, carbohydrate, vitamin $\mathrm{C}$ and calcium was calculated using the Dankost 2000 dietary assessment software (Danish Catering Center, Herlev, Denmark).

\section{Determination of zinc absorption}

All subjects' individual background radiation was measured at baseline by whole-body retention and $\mathrm{Zn}$ absorption from the full-day diets was estimated by whole-body retention of ${ }^{65} \mathrm{Zn} 21 \mathrm{~d}$ after consumption of extrinsically labelled meals, which also accounted for baseline for the following intervention week. The natural decay of the radioisotope was accounted for in the calculations of the amount of absorbed isotope. The measurements were performed in a lead-lined steel chamber with four NE110 plastic scintillator blocks (Nuclear Enterprises Ltd, Edinburgh, UK) connected to conventional nuclear electronic modules and a multichannel nalyser system. The counting efficiency and energy window settings were established through measurements of water-filled phantoms whose outlines and weights were approximately equal to those of the subjects of the present study. The phantoms were filled with the amount of isotope corresponding to the amount received by each subject. In the actual set-up and with the energy window used, the overall counting efficiency for ${ }^{65} \mathrm{Zn}$ evenly distributed in a $77 \mathrm{~kg}$ phantom was approximately $20 \%$. To minimize contamination by atmospheric background activity, all subjects had a shower, washed their hair and were dressed in hospital clothing 


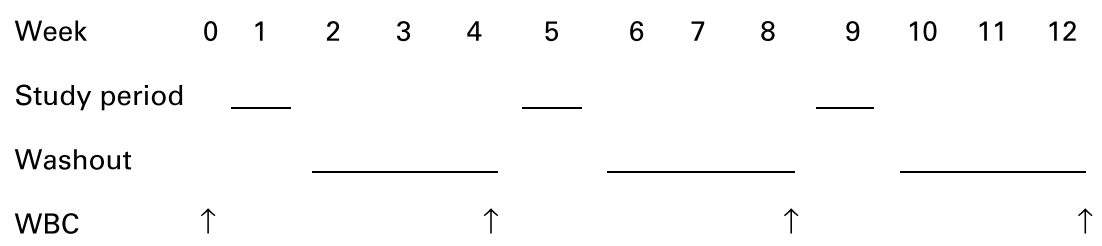

Fig. 1. Design of the study, indicating three study periods of $5 \mathrm{~d}$ with $21 \mathrm{~d}$ of washout and four whole-body countings (WBC) for measurements of zinc absorption. Isotope ${ }^{65} \mathrm{Zn}$ was administered to all main meals on all five days of the study periods.

before each measurement. The counting time was $10 \mathrm{~min}$, and the results were corrected for chamber background radiation and the subject's background radiation radioisotope level measured $3 \mathrm{~d}$ before the beginning of the first intervention period. All results from the determination of radioactivity measurements were corrected for the physical decay of the isotope. Results are expressed as fractional absorption (percentage of ingested amount) and total absorption.

\section{Chemical analysis}

$\mathrm{Zn}$ content was analysed in triplicate portions of complete $10 \mathrm{MJ}$ diets (Knudsen et al. 1996). The foods were homogenized, lyophilized and microwave-digested (MES-1000; CEM Corporation, Matthews, NC, USA) with $\mathrm{HNO}_{3} 65 \%$ suprapur (Merck, Darmstadt, Germany) and $30 \% \mathrm{H}_{2} \mathrm{O}_{2}$ suprapur (Merck). Zn was measured by atomic absorption spectroscopy (Spectra AA-200 VARIAN; Varian Techtron Pty Ltd, Victoria, Australia). The $\mathrm{Zn}$ standard was prepared from a standard solution of $1000 \mathrm{mg}$ Zn/l (Tritisol ${ }^{\circledR}$; Merck) and a reference diet (Standard Reference Material 1548a, Typical Diet; National Institute of Standards and Technology, Gaithersburg, MD, USA) was analysed in the same run with a certified value of 24.6 (SD 1.79) $\mu \mathrm{g} \mathrm{Zn/g}$. Analysed values were (n 2) $22.7 \mu \mathrm{g} / \mathrm{g}$ and $25.3 \mu \mathrm{g} / \mathrm{g}$. The concentration of phytic acid was determined using the method of Carlsson et al. (2001).

\section{Statistical analysis}

All analyses and calculations were performed using the Strategic Analysis System software package, version 8.2 (SAS Institute, Cary, NC, USA). Univariate mixed-model ANOVA were performed in the procedure MIXED. In the statistical model, the $\mathrm{Zn}$ absorption measured at the end of each period was evaluated as the dependent variable. Treatment, order, period and treatment $\times$ order were included as independent fixed variables. Subjects were included as a random effect. Homogeneity of variance and normal distribution among random effects were investigated by plots of residuals. The Shapiro-Wilk test for normal distribution was performed.

\section{Results}

Breakfast, lunch and dinner meals were all extrinsically labelled and consumed at the department under supervision of a staff member. Compliance to the dietary intervention was evaluated to be high. All subjects remained weight-stable throughout the study.

The dietary composition of the whole-day diet $(10 \mathrm{MJ})$ is outlined in Table 2. Content of protein and fat was higher in the meat diets, since carbonated drinks substituted the equivalent energy contribution from the meat. The evening snack, the only meal not extrinsically labelled, contained approximately $10 \%$ of the daily intake of $\mathrm{Zn}$ in the meat diets and $18 \%$ of the $\mathrm{Zn}$ content in the vegetarian diet. The amount of $\mathrm{Zn}$ was evenly distributed in the three main meals.

The average daily energy intake was 10 (SE 0.18) MJ. The intake, fractional absorption and total absorption of $\mathrm{Zn}$ are outlined in Table 3. The $\mathrm{Zn}$ intake from the meat diets was 20$24 \%$ higher than that from the vegetarian diet. Fractional $\mathrm{Zn}$ absorption from the meat diets was not different from the vegetarian diet. However, the total $\mathrm{Zn}$ absorption from the meat diets increased significantly, by $45 \%(P=0.009)$ and $50 \%$ $(P<0.001)$ for the Danish meat diet and Polish meat diet, respectively, compared with the vegetarian diet. No difference was observed in either fractional or total $\mathrm{Zn}$ absorption between the two meat diets.

\section{Discussion}

A meat intake of $60 \mathrm{~g}$ in each of the three main courses of the day did not lead to increased fractional absorption of $\mathrm{Zn}$ but resulted in increased total absorption compared with the vegetarian diet. The fractional and total absorption of $\mathrm{Zn}$ from the three diets was in the range of $24-27 \%$ and $1.8-2.7 \mathrm{mg} / \mathrm{d}$, respectively. Several other studies investigating absorption of $\mathrm{Zn}$ from diets high in phytic acid have found similar absorption ratios (Sandström et al. 1987b, 1989; Hunt et al. 1995, 1998).

The three principal dietary factors influencing absorption and utilization of $\mathrm{Zn}$ are the content of inositol phosphates (phytic acid; Nävert et al. 1985; Sandström et al. 1987a), the total Zn content of the meal (Sandström et al. 1980, 1987a) and the amount and source of protein (Sandström et al. 1980, 1987c, 1989). Previous studies investigating the potential enhancing

Table 2. Energy, macronutrient, micronutrient and phytic acid content of the $10 \mathrm{MJ}$ diet

\begin{tabular}{lcc}
\hline & Meat diets & Vegetarian diet \\
\hline Protein $(\mathrm{g})$ & 84 & 48 \\
Fat $(\mathrm{g})$ & 85 & 76 \\
Carbohydrate $(\mathrm{g})$ & 313 & 371 \\
Dietary fibre $(\mathrm{g})$ & 29 & 29 \\
Vitamin C (mg) & 51 & 51 \\
Ca $(\mathrm{mg})$ & 430 & 540 \\
Fe $(\mathrm{mg})^{*}$ & $10 \cdot 3$ & 9.5 \\
Phytic acid $(\mu \mathrm{mol})^{*}$ & 1280 & 1160 \\
Phytic acid:Zn & $9: 1$ & $10: 1$ \\
\hline *Analysed values. & &
\end{tabular}


Table 3. Content of analysed zinc, the average fractional absorption and total absorption of zinc in whole-day diets from two meat-based diets and the same diet without meat (vegetarian diet)

(Mean values with their standard error for twelve subjects per group)

\begin{tabular}{|c|c|c|c|c|c|c|}
\hline & \multicolumn{2}{|c|}{$\begin{array}{l}\text { Total Zn intake } \\
(\mathrm{mg} / \mathrm{d})\end{array}$} & \multicolumn{2}{|c|}{$\begin{array}{c}\text { Fractional Zn } \\
\text { absorption } \\
(\%)\end{array}$} & \multicolumn{2}{|c|}{$\begin{array}{l}\text { Total } \mathrm{Zn} \\
\text { absorption } \\
(\mathrm{mg} / \mathrm{d})\end{array}$} \\
\hline & Mean & SE & Mean & $\mathrm{SE}$ & Mean & SE \\
\hline Danish meat diet & $9 \cdot 4$ & 0.19 & 27 & 1.9 & $2 \cdot 6$ & $0 \cdot 19^{a}$ \\
\hline Polish meat diet & 9.9 & 0.14 & 27 & $1 \cdot 2$ & $2 \cdot 7$ & $0 \cdot 14^{\mathrm{a}}$ \\
\hline Vegetarian diet & 7.5 & 0.18 & 24 & $2 \cdot 6$ & 1.8 & $0.21^{\mathrm{b}}$ \\
\hline
\end{tabular}

${ }^{a, b}$ Mean values within a column with unlike letter superscripts were significantly different $(P<0 \cdot 05)$.

factor of an additional protein intake have all been based on meals or diets with different contents of phytic acid (Sandström \& Cederblad, 1980; Sandström et al. 1989; Hunt et al. 1998), whereas, in the present study, the content of phytic acid was kept at a constant level in all three meals to ensure that this contributing effect on $\mathrm{Zn}$ absorption was equal in all diets.

Due to a considerable contribution of $\mathrm{Zn}$ from the pork meat, the concentration of $\mathrm{Zn}$ in the meat diets in the present study was $20-24 \%$ higher than in the vegetarian diet. The dietary $\mathrm{Zn}$ content has been reported in several studies to be the most important single factor for the fractional absorption of $\mathrm{Zn}$, with decreased fractional absorption of $\mathrm{Zn}$ from meals with higher Zn content (Sandström et al. 1987a; Hunt et al. 1995; Lonnerdal, 2000). In the present study no difference was observed in the fractional absorption of $\mathrm{Zn}$ between the vegetarian diet and the meat diets. A higher $\mathrm{Zn}$ content in the meat diets has possibly counterbalanced a potential enhancing effect of meat on the absorption of $\mathrm{Zn}$ by lowering the fractional absorption (Table 3 ). An advantage of an intake of meat on the absorption of $\mathrm{Zn}$ is reflected in the significant increased total absorption of $\mathrm{Zn}$ as observed by Hunt et al. (1995).

$\mathrm{Zn}$ absorption can be measured with high precision and accuracy by the extrinsic labelling of meals with the radioisotope ${ }^{65} \mathrm{Zn}$ followed by analysis of the absorbed isotope in a whole-body counter. The method has been validated by Arvidsson et al. (1978). Use of this method assumes that isotopic exchange occurs between the added isotope and the dietary $\mathrm{Zn}$, whereby a common pool is formed (Flanagan et al. 1985; Gallaher et al. 1988; Egan et al. 1991). In the present study, only selected parts of the meals were labelled (the pâté at breakfast and lunch and the casserole with rice or pasta in the dinner meal). All components of the meal were consumed together and, as the $\mathrm{Zn}$ content of the meal would have been mixed in one pool, it was assumed that complete isotopic exchange occurred.

Like $\mathrm{Zn}, \mathrm{Fe}$ is a divalent ion and absorption is significantly inhibited by a concomitant intake of phytic acid (Hallberg et al. 1987) and possibly enhanced by intake of meat (Bæch et al. 2003). Differences in the absorption ratio of Fe when comparing single meal studies with whole diet studies have indicated that the former overestimate the effects of dietary enhancers and inhibitors on Fe absorption (Cook et al. 1991), and that shortterm measurements of absorption overestimate differences in Fe bioavailability between diets (Hunt \& Roughead, 2000). To our knowledge, no similar studies investigating a similar discrepancy in $\mathrm{Zn}$ absorption between whole meal studies and single meal studies have been published but similar differences in absorption of $\mathrm{Zn}$ from whole meal studies compared with single meal studies may occur. In the present study design a whole diet on five consecutive days was carried out in order to eliminate possible effects of a single meal design and to imitate the natural diet.

To ensure that the meat diets and vegetarian diets were isoenergetic, carbonated beverage was served at all vegetarian meals. The beverage did not contain ingredients that are believed to affect $\mathrm{Zn}$ absorption. This design may give limitations for practical applications of the results, since vegetarians most likely consume other food items such as bread or vegetables to compensate for the lack of meat as well as sources of compensatory protein. Other food items may result in elevated phytic acid contents of the vegetarian meals and thereby a higher proportion of inhibitors in the total diet. An additional limitation to the study could be the lower $\mathrm{Zn}$ content in the vegetarian diet. As described previously, the $\mathrm{Zn}$ content in the meal influences the fractional absorption of $\mathrm{Zn}$, but in order to investigate the absorption from the natural diets, $\mathrm{Zn}$ content was not adjusted between the three diets by addition of inorganic $\mathrm{Zn}$. If the $\mathrm{Zn}$ content had been equal between the two diets, the total absorption of $\mathrm{Zn}$ might not have differed.

The average fractional absorption of $\mathrm{Zn}$ in the present study of $24-27 \%$ reflected the absorption reported by similar studies, but was substantially lower than the estimated $40 \%$ fractional absorption upon which recommended intakes in the Nordic Nutrition Recommendations (www.norden.org) are based. The lower absorption in the present study is most likely due to a high content of phytic acid in the diet.

In conclusion, fractional $\mathrm{Zn}$ absorption in this whole meal study was similar in the vegetarian and meat diets of meals with equal phytic acid contents, most likely due to the lower amount of $\mathrm{Zn}$ in the vegetarian diet. However, the total absorption of $\mathrm{Zn}$ from the vegetarian diet was significantly lower than from the meat diets, which is most likely associated with the higher intakes of protein and $\mathrm{Zn}$ in the meat diets. A daily intake of $180 \mathrm{~g}$ meat resulted in a significantly increased total absorption of $\mathrm{Zn}$ compared with the vegetarian diet.

\section{Acknowledgements}

This study is dedicated to the memory of the late Professor Brittmarie Sandström, who initiated this work. The work was part of the 5th Framework Programme SUSPORKQUAL (QLK5-200000162) of the European Commission. It does not necessarily reflect its views and in no way anticipates the Commission's future policy in this area. We thank all the participating subjects for their enthusiasm and interest in the study. The staff of the metabolic kitchen, Berit Hoielt and Yvonne Rasmussen, and the laboratory technicians, Hanne Lysdal Petersen and Ella Jessen, are thanked for their skilful handling of diets, subjects, blood sampling and analysis of samples. Laboratory technologists Susanne Svalling and Pia Christensen, The University Hospital, are thanked for the measurements of whole-body isotopic retention. Professor Henryk Fandrejewski, The Kielanowski Institute of Animal Physiology and Nutrition, Polish Academy of Sciences, Jablonna, Poland and Dr Gunilla Lindahl, Danish Institute of Agricultural Sciences, Tjele, Denmark are thanked for providing the pork meat. 


\section{References}

Arvidsson B, Cederblad Å, Björn-Rasmussen E \& Sandström B (1978) A radionuclide technique for studies of zinc absorption in man. Int $\mathrm{J} \mathrm{Nucl}$ Med Biol 5, 104-109.

Bach Kristensen M, Hels O, Morberg CM, et al. (2005) Pork meat increases iron absorption from a five days fully controlled diet when compared to a vegetarian diet with similar vitamin $\mathrm{C}$ and phytic acid content. Br J Nutr 94, 78-83.

Bæch SB, Hansen M, Bukhave K, Jensen M, Sorensen SS, Kristensen L, Purslow PP, Skibsted LH \& Sandström B (2003) Nonheme-iron absorption from a phytate-rich meal is increased by the addition of small amounts of pork meat. Am J Clin Nutr 77, 173-179.

Brown KH \& Wuehler SE (2000) Zinc and Human Health. Ottawa, Ont: Micronutrient Initiative.

Carlsson NG, Bergman EL, Skoglund E, Hasselblad K \& Sandberg AS (2001) Rapid analysis of inositol phosphates. J Agric Food Chem 49, 1695-1701.

Cook JD, Dassenko SA \& Lynch SR (1991) Assessment of the role of nonheme-iron availability in iron balance. Am J Clin Nutr 54, 717-722.

Egan CB, Smith FG, Houk RS \& Serfass RE (1991) Zinc absorption in women: comparison of intrinsic and extrinsic stable-isotope labels. Am J Clin Nutr 53, 547-553.

Flanagan PR, Cluett J, Chamberlain MJ \& Valberg LS (1985) Dualisotope method for determination of human zinc absorption: the use of a test meal of turkey meat. J Nutr 115, 111-122.

Gallaher DD, Johnson PE, Hunt JR, Lykken GI \& Marchello MJ (1988) Bioavailability in humans of zinc from beef: intrinsic vs extrinsic labels. Am J Clin Nutr 48, 350-354.

Gibson RS (1994) Content and bioavailability of trace elements in vegetarian diets. Am J Clin Nutr 59, Suppl., 1223S-1232S.

Hallberg L, Rossander L \& Skanberg AB (1987) Phytates and the inhibitory effect of bran on iron absorption in man. Am J Clin Nutr 45, 988-996.

Hunt JR (2002) Moving toward a plant-based diet: are iron and zinc at risk? Nutr Rev 60, 127-134.

Hunt JR (2003) Bioavailability of iron, zinc, and other trace minerals from vegetarian diets. Am J Clin Nutr 78, Suppl., 633S-639S.

Hunt JR, Gallagher SK, Johnson LK \& Lykken GI (1995) High- versus low-meat diets: effects on zinc absorption, iron status, and calcium, copper, iron, magnesium, manganese, nitrogen, phosphorus, and zinc balance in postmenopausal women. Am J Clin Nutr 62, 621-632.

Hunt JR, Lykken GI \& Mullen LK (1991) Moderate and high amounts of protein from casein enhance human absorption of zinc from wholewheat or white rolls. Nutr Res 11, 413-418.

Hunt JR \& Roughead ZK (2000) Adaptation of iron absorption in men consuming diets with high or low iron bioavailability. Am J Clin Nutr 71, 94-102.
Hunt JR, Matthys LA \& Johnson LK (1998) Zinc absorption, mineral balance, and blood lipids in women consuming controlled lactoovovegetarian and omnivorous diets for $8 \mathrm{wk}$. Am J Clin Nutr 67, 421-430.

Jenkins DJ, Kendall CW, Marchie A, Jenkins AL, Augustin LS, Ludwig DS, Barnard ND \& Anderson JW (2003) Type 2 diabetes and the vegetarian diet. Am J Clin Nutr 78, Suppl., 610S-616S.

Johnson JM \& Walker PM (1992) Zinc and iron utilization in young women consuming a beef based diet. J Am Diet Assoc 92, 1474-1478.

Knudsen E, Sandström B \& Solgaard P (1996) Zinc, copper and magnesium absorption from a fibre-rich diet. J Trace Elements Med Biol 10, $68-76$.

Lonnerdal B (2000) Dietary factors influencing zinc absorption. J Nutr 130, Suppl., 1378S-1383S.

Murphy SP \& Allen LH (2003) Nutritional importance of animal source foods. J Nutr 133, Suppl., 3932S-3935S.

Nävert B, Sandström B \& Cederblad $\AA$ (1985) Reduction of the phytate content of bran by leavening in bread and its effect on zinc absorption in man. Br J Nutr 53, 47-53.

Position of the American Dietetic Association and Dietitians of Canada (2003) Vegetarian diets. J Am Diet Assoc 103, 748-765.

Sandström B, Almgren A, Kivistö B \& Cederblad Å (1987a) Zinc absorption from meals based on rye, barley, oatmeal, triticale and wholewheat. J Nutr 117, 1898-1902.

Sandström B, Almgren A, Kivistö B \& Cederblad A (1989) Effects of protein level and protein source on zinc absorption in humans. J Nutr 119 , 48-53.

Sandström B, Arvidsson B, Cederblad A \& Bjorn-Rasmussen E (1980) Zinc absorption from composite meals. I. The significance of wheat extraction rate, zinc, calcium, and protein content in meals based on bread. Am J Clin Nutr 33, 739-745.

Sandström B \& Cederblad $\AA$ (1980) Zinc absorption from composite meals. II. Influence of the main protein source. Am J Clin Nutr 33, $1778-1783$.

Sandström B, Cederblad Å, Stenquist B \& Andersson H (1990) Effect of inositol hexaphosphate on retention of zinc and calcium from the human colon. Eur J Clin Nutr 44, 705-708.

Sandström B, Davidsson L, Kivistö B, Hasselblad C \& Cederblad A (1987b) The effect of vegetables and beet fibre on the absorption of zinc in humans from composite meals. Br J Nutr 58, 49-57.

Sandström B, Kivistö B \& Cederblad Å (1987c) Absorption of zinc from soy protein meals in humans. J Nutr 117, 321-327.

Waldmann A, Koschizke JW, Leitzmann C \& Hahn A (2003) Dietary intakes and lifestyle factors of a vegan population in Germany: results from the German Vegan Study. Eur J Clin Nutr 57, 947-955.

Zheng JJ, Mason JB, Rosenberg IH \& Wood RJ (1993) Measurement of zinc bioavailability from beef and a ready-to-eat high-fiber breakfast cereal in humans: application of a whole-gut lavage technique. Am J Clin Nutr 58, 902-907. 